\title{
A IMPRENSA BRASILEIRA E OS ASPECTOS AMBIENTAIS DA ERA DA DIVERSIDADE ENERGÉTICA
}

\author{
Arnaldo Carlos Muller*, Roberto Tuyoshi Hosokawa**, João Carlos Garzel Leodoro da Silva*** \\ *Eng. Florestal, Dr., Pontifícia Universidade Católica, PUCPR - muller@grimpa.org.br \\ **Eng. Florestal, Dr., Depto. de Ciências Florestais, UFPR - hosokawa@pesquisador.cnpq.br \\ ***Eng. Florestal, Dr., Depto. de Economia Rural e Extensão, UFPR - garzel@ufpr.br \\ Recebido para publicação: 09/02/2007 - Aceito para publicação: 10/07/2007
}

\begin{abstract}
Resumo
Este estudo teve por objetivo avaliar o crescimento do interesse de parcela da imprensa brasileira acerca dos aspectos ambientais da energia nos últimos dez anos, através do incremento do número e do conteúdo de textos versando sobre a questão. O método de trabalho foi embasado em pesquisas bibliográficas e em matérias impressas editadas no decênio entre 1997 e 2006, em um jornal e em uma revista quinzenal de negócios, ambos de circulação nacional. A pesquisa também enfocou o conteúdo mais notável desses textos. Foram pesquisados 4.837 textos que se referiam a energia, dos quais, $26,31 \%$ referiam-se a temas efetivamente ambientais. Assim, foi observado um progressivo aumento do número de textos a partir de 2001, bem como da sua qualidade informativa. Merece destaque o crescimento do enfoque em fontes alternativas de energia, como as da biomassa e a solar. Foi notório o aumento da sensibilidade da imprensa às questões energéticas, considerando que os textos, inicialmente resumidos, ganharam progressivamente mais espaço e conteúdo, sintoma da importância dada à matéria. As fontes energéticas mais tratadas foram os combustíveis fósseis, a nuclear, a de biomassa, a solar e a hidráulica. Também foi notado que os picos de intensidade estiveram relacionados com períodos de crises energéticas regionais, bem como às tendências mundiais da questão.

Palavras-chave: Energia e meio ambiente; mídia; imprensa; energias alternativas.
\end{abstract}

\begin{abstract}
The Brazilian press and the environmental aspects of the energy diversity era. The objective of this study was to evaluate the growth of the interest of the Brazilian press in the environmental aspects of the energy in the last ten years, through the increment of the number of texts and contents dealing with the topic. Its work method was based on researches of indexes and on published materials, from 1997 to 2006, in a newspaper and in a biweekly business magazine, both of national circulation. The research also focused the most notable contents of these texts. A total of 4,837 texts referring to energy were researched and out of the analyzed texts, $26.31 \%$ referred specifically to environmental themes. A progressive increase in the number of texts since 2001 was observed, as well as the informative quality. It is remarkable the growth of emphasis in alternative sources of energy, such as the biomass and the solar sources. The increase of the awareness of the press to the energetic topics was notorious, considering that the texts, initially summarized, progressively gained more space and contents, a symptom of the importance given to the subject. The most commonly energy sources dealt with were the fossil fuels, nuclear, biomass, solar and hydraulic sources. It was also noticed that the peak of intensity were related with the periods of regional energy crisis, as well as the world trends of the topic.

Keywords: Energy and environment; media; press; alternative energy.
\end{abstract}

\section{INTRODUÇ̃̃O}

A percepção da finitude da era do petróleo, ainda que venha se prorrogando à luz da descoberta e recuperação de campos petrolíferos em vários locais do mundo, tem provocado uma corrida efetiva em busca de novas alternativas energéticas, compreendendo-se que a energia é a principal mola propulsora do desenvolvimento das nações.

Energia é conceituada como a capacidade para realizar trabalho. O comentarista Martin Wolf, do jornal Valor Econômico, resgatou uma forma interessante para interpretar esse conceito:

FLORESTA, Curitiba, PR, v. 38, n. 2, abr./jun. 2008. 
Como observou Bjorn Lomborg, o controvertido acadêmico dinamarquês, "se pensarmos por um momento na energia que empregamos em termos de 'criados', com cada um deles dotado da mesma potência de um ser humano, cada pessoa na Europa Ocidental é hoje atendida por 150 criados, cerca de 300 nos EUA e, mesmo na Índia, cada pessoa tem 15 criados para ajudá-la" - The Sceptical Environmentalist (CAMBRIDGE UNIVERSITY PRESS, 2001). Não foi por acaso que a revolução energética resultou no (quase total) desaparecimento da escravidão e da servidão. As máquinas puseram fim à servidão e libertaram as mulheres da labuta enfadonha, fatigante e quotidiana no lar. Só onde máquinas não podem (até agora) substituir seres humanos - nos cuidados prestados a crianças e idosos, por exemplo - isso ainda não é verdade (WOLF, 2006).

Observa-se uma verdadeira corrida tecnológica no setor energético mundial, em especial no bojo das discussões sobre o aquecimento global. Discutem-se tanto novas fontes energéticas como a otimização dos usos energéticos. Os destaques são, sem dúvida, para o desenvolvimento e emprego das energias chamadas alternativas. Nota-se maior avanço nas pesquisas sobre meios de transporte mais eficientes, equipados com novos sistemas de propulsão, com motores de combustão interna, com sistemas híbridos e, mais recentemente, com pilhas de hidrogênio, sendo testados vários combustíveis, de forma que venham a ocupar o lugar dos derivados do petróleo.

Esses avanços tecnológicos já não são inexpressivos e nem ocorrem despercebidamente, muito pelo contrário. Os institutos de pesquisa tecnológica, muitos pesquisadores, bem como inúmeros representantes do Terceiro Setor vêm trazendo a público seus trabalhos, suas inquietudes e seus protestos. Os veículos de comunicação que recebem e divulgam essas questões já não são somente os especializados, mas se estendem a praticamente todos os meios da mídia. Essa abertura, contudo, é muito recente - se reduz à última década -, mas se mostra muito vigorosa, notadamente pelas repercussões sociais, econômicas e ambientais açambarcadas pelo tema.

No conceito de Ribeiro; Real (2006), a era da diversidade energética em que o mundo está entrando conduzirá para soluções em que as alternativas tecnológicas dependerão das vocações regionais, vistas como única via para viabilizar os custos da disponibilização energética. Cada região de um país, ou mesmo cada país integralmente, deverá adotar as tecnologias e combustíveis que sejam mais convenientes para o equilíbrio das bases de oferta, associadas às condições econômicas, sociais e ambientais. O componente da sustentabilidade acrescenta ainda à questão o ônus da projeção dos efeitos dessas escolhas, no espaço e no tempo, impondo que as decisões gerem condições duráveis por muitas gerações.

A mídia já percebeu esse fato, e muitos textos mostram que ela vem se especializando rapidamente nas questões energéticas, incluídas as diversas formas energéticas disponibilizadas (energia elétrica, mecânica, térmica, luminosa ou química). Essa especialização, vale destacar, incluiu a popularização das tecnologias do setor, através de um esforço da imprensa em "traduzir" os jargões técnicos à compreensão da sociedade leiga.

Segundo Rosa (2001), se algum assunto se desloca de seu "caderno" editorial tradicional para ocupar espaços de maior relevância no veículo de comunicação, esse assunto "entrou na pauta", ou seja, passou a ter relevância expressiva, que justifica atenção especial. O tema energético-ambiental vem ganhando não somente deslocamento de "caderno", como também passou a receber destaque como matéria de capa, suplementos especiais e grande densidade de freqüência. É mais do que tempo para que os profissionais do setor energético se apercebam desse fato e a ele reajam, passando a participar dessa interessante fase da popularização de um tema tradicionalmente restrito à comunidade tecnológica, mas de grande importância social.

O objetivo do presente artigo é avaliar o crescimento do interesse da imprensa brasileira acerca das questões energéticas, em especial sua sensibilização sobre os aspectos ambientais da energia, durante os últimos dez anos.

\section{MATERIAL E MÉTODO}

Foram empregadas fontes distintas de dados da mídia escrita, contemplando o universo temporal do período entre 1997 e 2006. Para a avaliação do incremento de interesse da imprensa, considerou-se que as instituições públicas e privadas, bem como a sociedade civil organizada encaminham ou disponibilizam à mídia escrita - entendida aqui como o grande conjunto de veículos de comunicação notícias e informações na maioria das vezes já na forma de textos praticamente prontos para publicação. Muitos veículos se servem dessas fontes e, assim, em uma mesma data, a mesma notícia é veiculada várias vezes. Dependendo do interesse que a notícia pode gerar junto aos leitores, varia o número de veículos que a publicam. 
Para encaminhar a pesquisa, decidiu-se pela contagem do número de textos em dois meios de comunicação impressa: Folha de S. Paulo, um jornal diário, e Exame, uma revista de negócios quinzenal, ambos de alcance nacional e dirigidos ao público de classe média-alta brasileira. Esses dois veículos propiciam arquivos catalográficos de buscas, disponibilizados por meio eletrônico sob controle de acesso das editoras, onde se pôde pesquisar o número e conteúdo dos textos publicados nos últimos dez anos, compreendidos entre 1997 e 2006.

As buscas foram feitas em 8.707 textos, dos quais 6.308 foram verificados no respectivo jornal e 2.399 na revista. Do conjunto analisado, $4,53 \%$ dos textos referiam-se a temas efetivamente ambientais, sendo menos freqüentes no jornal $(3,58 \%)$ do que na revista $(6,33 \%)$.

No que diz respeito aos conteúdos, a pesquisa incluiu, além dos dois veículos de comunicação, outros três jornais, um de nível nacional (Gazeta Mercantil) e dois de nível local (Gazeta do Povo e O Estado do Paraná). A essas fontes foram somadas pesquisas bibliográficas e levantamentos em bancos de dados de fontes oficiais (ministérios das Minas e Energia e do Meio Ambiente, Eletrobrás e órgãos setoriais do Sistema Nacional do Meio Ambiente), relacionados à ora chamada era da diversidade energética.

\section{RESULTADOS}

\section{O comportamento da imprensa}

O número de textos com conteúdo técnico - ainda que comunicado com linguajar acessível à população não-especializada - que fluiu na imprensa refletiu um fator conjuntural preponderante: a estiagem que ocorreu nas regiões de maior importância econômica do território nacional no início da década de 2000, influenciando marcadamente o suprimento de energia elétrica no Brasil. A questão energética que até então tinha relativamente pequena importância no conjunto das notícias veiculadas, passou a receber espaço permanente.

Esse espaço deveu-se, certamente à importância do suprimento energético no panorama da infraestrutura nacional, e a grande preocupação que passou a ser percebida nas entrelinhas dos textos foi a vulnerabilidade do Brasil a novas situações climáticas adversas, para cujo enfrentamento o país comprovadamente não está preparado.

Antes de se verificar o componente ambiental, introduzido necessariamente a partir do momento em que passaram a ser discutidas fontes alternativas e pressões da sociedade civil organizada sobre o uso dos recursos hídricos para a geração energética, devem-se analisar as freqüências dos textos que abordaram o tema energético.

Iniciando pelo jornal, a incidência do tema ao longo dos anos comportou-se como mostra a figura 1. Observa-se por essa figura, que durante o ano de 2001, quando ocorreu o "apagão" elétrico nacional - que evidentemente foi notícia graças às suas repercussões junto à população -, houve expressivo incremento do número de textos, atingindo 1622, identificados em um só diário.

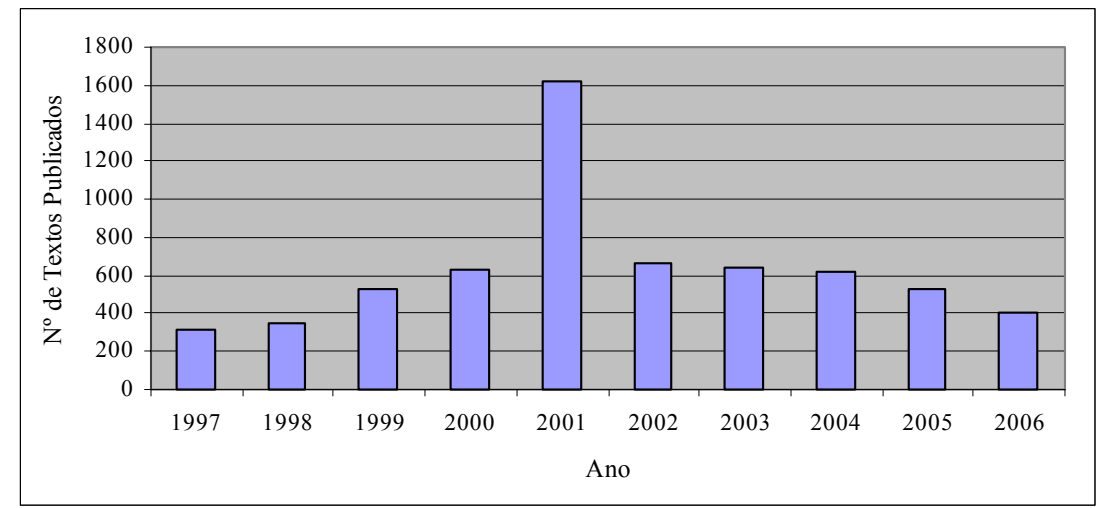

Figura 1. Evolução do número de textos de jornal abordando questões energéticas.

Figure 1. Increment of the quantity of newspaper excerpts concerning energy aspects.

Na figura 2, nota-se, à luz do número de textos gerais sobre energia, a incidência relativa daqueles referentes ao tema energia e meio ambiente.

FLORESTA, Curitiba, PR, v. 38, n. 2, abr./jun. 2008. 


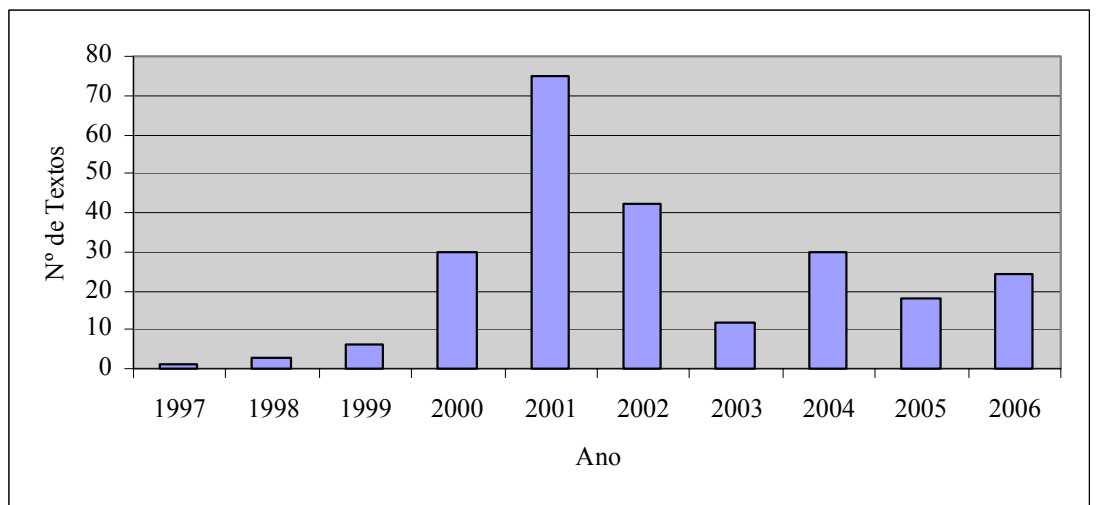

Figura 2. Evolução do número de textos de jornal abordando aspectos energético-ambientais.

Figure 2. Increment of the of newspaper excerpts concerning energy and environment aspects.

A figura 3 apresenta o número anual de textos referentes às várias modalidades de energia. Excluíram-se, naturalmente, os textos em que se mencionou a questão energética fora do contexto deste estudo, como, por exemplo, em questões políticas, econômicas e outras mais não referidas ao tema, mas sinônimas do termo "energia", tais como força pessoal, entusiasmo e vitalidade, freqüentes em textos referentes a aspectos psicológicos e emocionais (consideradas essas ocorrências, o número de citações excederia a 29.970 somente no jornal).

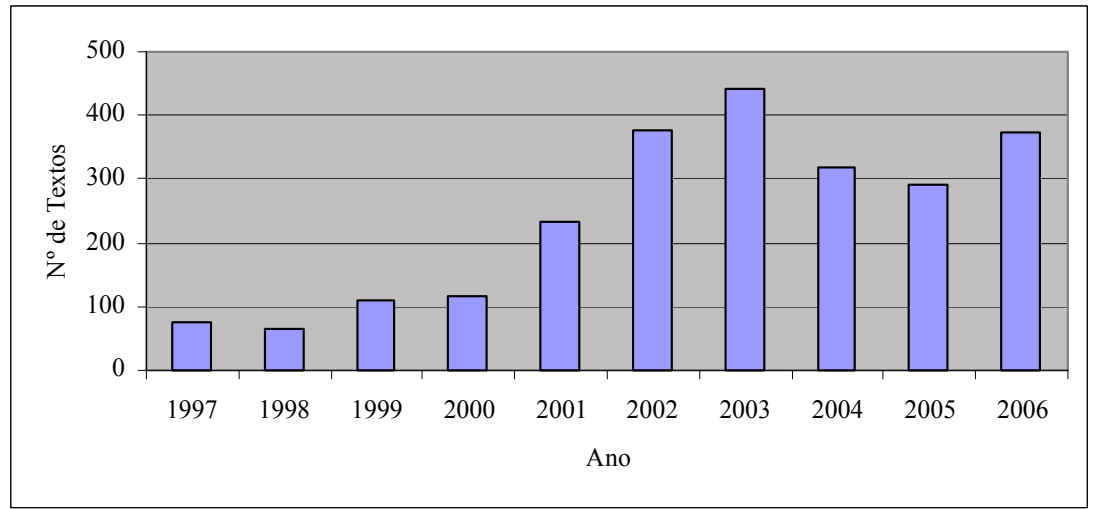

Figura 3. Evolução do número de textos de revista abordando questões energéticas nacionais.

Figure 3. Increment of the quantity of magazine excerpts concerning national energy aspects.

Sistematizando os textos de forma similar ao que se fez aos textos do jornal, ou seja, restringindo-se as pesquisas à incidência relativa de textos de conteúdo técnico referidos ao tema energia e meio ambiente, chegou-se ao resultado que se pode contemplar na figura 4.

Uma análise das figuras indica haver algumas correlações entre a freqüência da veiculação das notícias no jornal, com ápice no ano de 2000, ano em que ocorreu o mencionado "apagão", com os dados obtidos com a análise da revista, cujo conteúdo é mais reflexivo e aplicado aos negócios, alvo dos seus leitores. Cessando os efeitos ambientais que motivaram o "apagão", ambos os veículos de comunicação reduziram seu volume de textos com teor energético-ambiental, ainda que sem voltar ao número de textos veiculados no início da série histórica analisada. Esses dados servem para ilustrar a importância relativa do tema, à vista da sua densidade nos noticiários.

Situação interessante, porém, ocorreu na linha editorial da revista em 2006. Mantendo-se a distância das questões ambientais, estas repentinamente passaram a ocupar expressivo espaço em muitos exemplares desse ano, provavelmente pelas repercussões das notícias sobre o aquecimento planetário atribuídas ao uso de fontes energéticas à base de combustíveis fósseis - sobre o mundo dos negócios. 


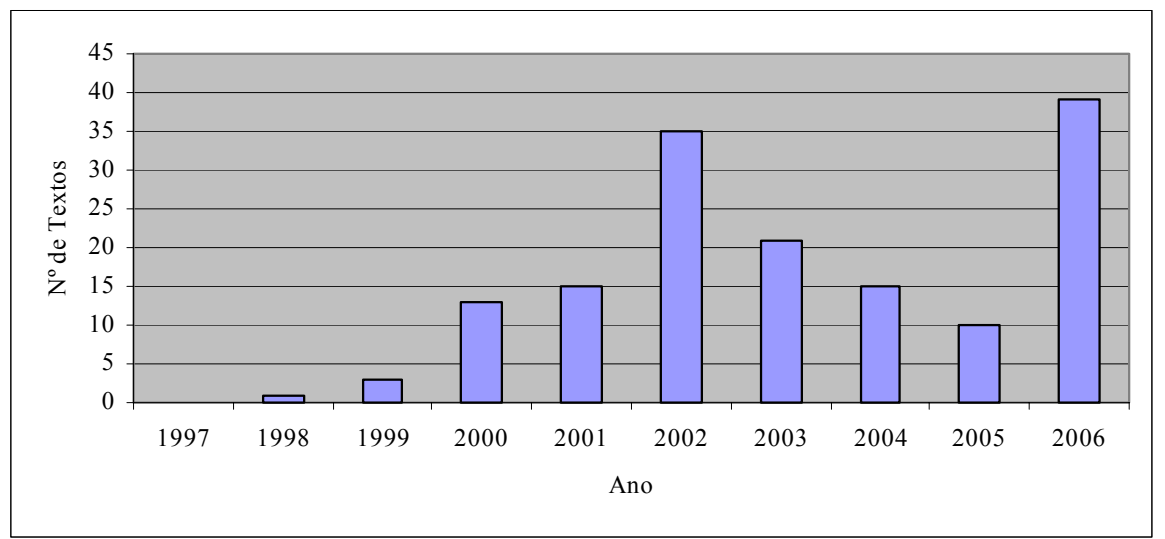

Figura 4. Evolução do número de textos de revista abordando aspectos energético-ambientais.

Figure 4. Increment of the quantity of magazine excerpts concerning energy and environment aspects.

Em que pese a expressividade dos números de textos relativos às questões de energia e meio ambiente, eles certamente representam uma taxa ínfima no universo dos textos diariamente expostos. Sendo assim, não obstante o notável incremento relativo dado às questões energéticas e ambientais, denotando o evidente despertar para a importância dessa questão, não se mostrou oportuno verificar-se o percentual relativo das matérias de energia e meio ambiente em relação às demais notícias.

Com essas considerações em tela, cabe discorrer sobre o conteúdo desses textos.

\section{As demandas energéticas}

Antes de se ingressar no tema central deste estudo, a diversidade energética, considerou-se adequado abordar as fontes de energia historicamente empregadas no país. Essa análise baseou-se nos dados do Balanço Energético Nacional (BEN), que é o documento oficial do Ministério das Minas e Energia (MME), atualizado anualmente e destinado a registrar estatísticas de energia. O BEN formula um retrato estratégico da Matriz Energética Nacional.

O Balanço, ao mesmo tempo em que revela os volumes de energia utilizados no Brasil por tipologia e consumidor, é também útil para orientar acerca das potencialidades de ofertas energéticas brasileiras. Um dos produtos derivados das análises do BEN é a evolução das ofertas internas relativas das várias fontes energéticas dos últimos 25 anos, apresentadas na figura 5.

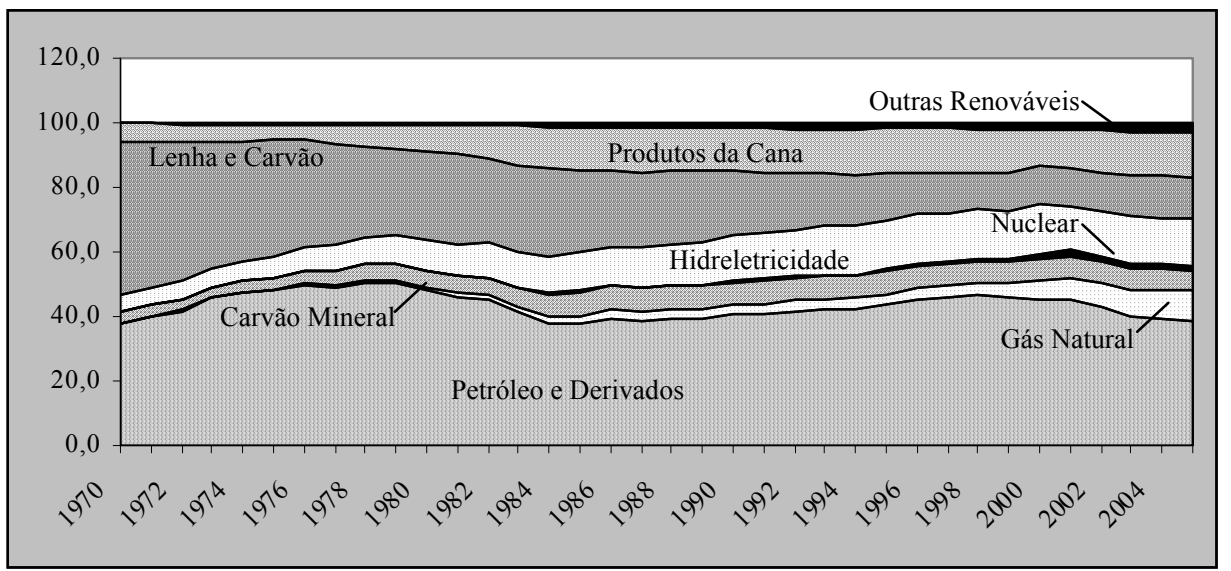

Fonte: Ministério das Minas e Energia/BEN - Balanço Energético Nacional.

Figura 5. Perfil da oferta interna relativa de energia no Brasil.

Figure 5. Outline of the relative internal energy availability in Brazil.

Pode ser observado, em uma análise sumária do Balanço Energético, o forte dinamismo nas ofertas e demandas energéticas, com aumentos significativos de alguns tipos de energia e redução relativa

FLORESTA, Curitiba, PR, v. 38, n. 2, abr./jun. 2008. 
de outros. Pelo verificado na figura 5, já se pode auscultar quais têm sido os principais impactos ambientais de origem energética no Brasil, e pode ser observada uma acentuada redução relativa do uso energético da biomassa florestal nas duas últimas décadas, coincidindo com o surgir das ofertas de gás natural. Os impactos decorrentes dessa constatação parecem ser positivos ao meio ambiente: reduziu-se a pressão sobre as florestas nativas e, graças aos benefícios ambientais do uso do gás natural, pode-se ter expectativas de melhoria da qualidade do ar urbano.

Essa figura mostra que a energia das biomassas derivadas da cana-de-açúcar cresceu até 1984 e desde então estagnou. Essa situação, a se avaliar pelas notícias da mídia e recentes decisões internacionais, não mais perdura, porém não é evidente na figura disponibilizada. Seu problema ambiental mais agudo está no avanço dessas culturas sobre áreas naturais, enquanto que, no econômico (e social), apontam-se riscos de redução de áreas de produção de alimentos em favor das áreas de produção bioenergética.

A oferta da energia hidrelétrica apresentou incremento constante no período, bem como, ainda que em taxa menor, a oferta de carvão mineral. Porém é interessante notar a escala relativa da energia hidrelétrica em comparação com as demais ofertas energéticas, parecendo ser descabidas as pressões ambientalistas contrárias a essa fonte energética, notadamente pelo seu baixo potencial poluidor comparado ao das demais energias ofertadas.

Outras ofertas de energia são menos importantes, como a nuclear, porque o parque gerador dessa fonte é exíguo. Mas começam a despontar ofertas de fontes alternativas, como a eólica, cujo volume ainda não a faz merecer destaque nessa figura. Não há registros de quaisquer problemas ambientais originados pela geração de energia nuclear no Brasil, muito menos da eólica, destacando-se, nesta, que sequer os problemas até então típicos de parques eólicos do exterior, tais como ruídos e danos à fauna alada, têm sido replicados em nossos parques.

Finalmente, é possível notar que a participação relativa do petróleo e derivados, que atingiu um máximo no final da década de 70 , tendeu a estabilizar-se, apresentando, no final do período de observação, uma pequena tendência a queda, em vista do aumento da participação relativa de outras fontes energéticas. O histórico de acidentes, no período contido nessa figura, envolvendo instalações, processos de sistemas de transporte e passivos ambientais da exploração, transposição, refino e distribuição, bem como os volumes de emissões decorrentes dos usos dessa fonte energética, revela uma conivência dos ambientalistas, especialmente considerando o potencial poluidor dessa fonte comparado ao das demais energias ofertadas.

A figura 6, com dados de 2005, do Ministério das Minas e Energia, desenha a situação das ofertas energéticas disponibilizadas nesse ano.

$\mathrm{Na}$ figura 6, é possível destacar o percentual do volume energético necessário para atender à demanda nacional, destacando-se a taxa do petróleo, seguida pela da energia hidráulica, dos produtos derivados da cana-de-açúcar e da lenha. Essa figura evidencia a classificação dos usuários pelas demandas da energia ofertada.

$\mathrm{Na}$ figura 7 verifica-se a crescente pressão da demanda energética nacional, em uma curva que evidencia a grande avidez de dois setores da economia nacional, o industrial e o de transporte. Ambos demandam, com maior ou menor intensidade, parte da energia produzida por todas as fontes anteriormente referidas.

Assim, corresponderia a esses dois setores, primordialmente, tanto reconhecer como tratar das conseqüências ambientais geradas no atendimento das suas necessidades. Reside aqui um aspecto pouco explorado pelo segmento econômico responsável pela geração energética, o que ressalta a preferência, notadamente aos que pretendem apresentar comportamentos ambientalmente corretos (por exemplo, via certificações ambientais), pelo emprego de energias limpas e pelo incentivo da geração destas, além da adoção de usos não impactantes da energia.

Essa tarefa não será simples, porém existem mecanismos disponíveis, inclusive de marketing, que poderiam ser adotados na consecução de soluções ambientais, uma vez que existem ganhos institucionais em se atender, criativamente, parcelas de mercado com produtos que contribuam com a qualidade de vida de seus clientes.

\section{A diversidade das fontes energéticas}

As referências sobre as fontes de energia geralmente perpassam por alguns conceitos tidos como reconhecidos, muito embora possam não o ser, pelo menos na plenitude de sua expressão. Um desses conceitos é o que trata da caracterização da fonte como renovável ou não-renovável. O outro diferencia as energias convencionais das alternativas. 


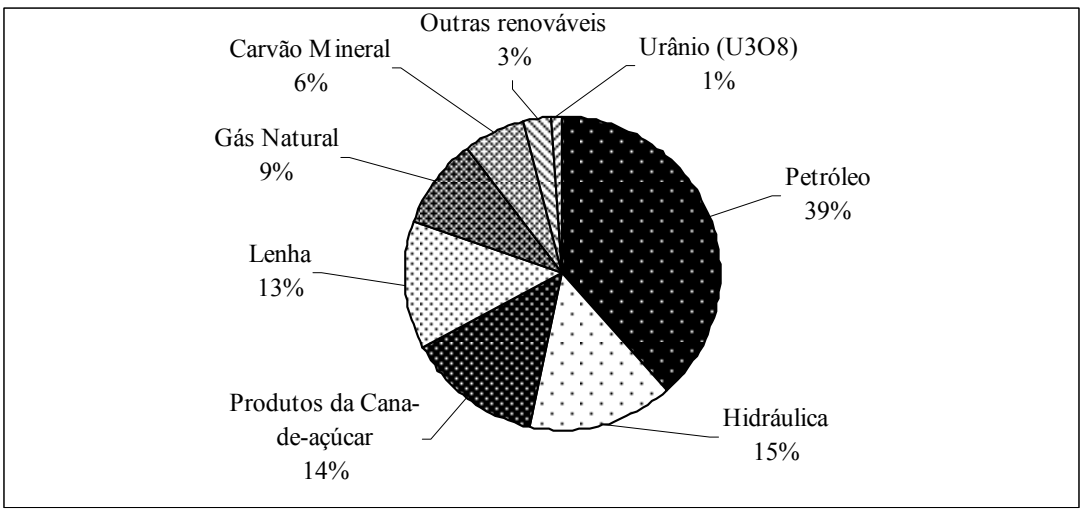

Fonte: Ministério das Minas e Energia/BEN - Balanço Energético Nacional.

Figura 6. Oferta interna de energia no Brasil em 2005.

Figure 6. Internal availability of energy in Brazil, in 2005.

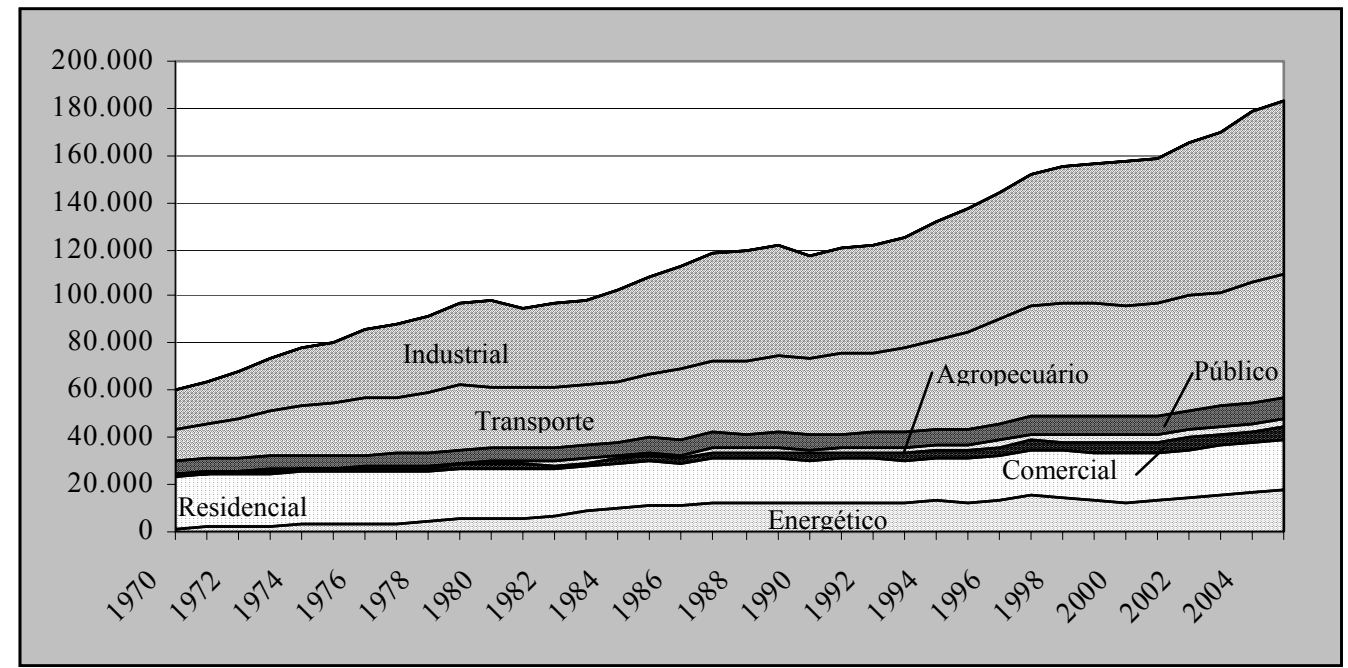

Fonte: Ministério das Minas e Energia/BEN - Balanço Energético Nacional.

Figura 7. Curvas históricas das demandas energéticas nacionais.

Figure 7. Historical curves of national energy consumption.

$\mathrm{Na}$ difusão desses termos, há autores que aumentam o conflito das conceituações. No jornal da Unicamp, universidade que tem se dedicado com destaque às pesquisas energéticas, o professor Carlos Tidei escreveu um artigo no qual afirma que "o conceito de energia alternativa, intensamente investigado no século passado, hoje é sinônimo de energia renovável" (TIDEI, 2002).

Todas as energias renováveis seriam alternativas? Certamente que não, e o Brasil possui em sua matriz energética uma fonte renovável - a água - que não está inteiramente no grupo das alternativas, como concluíram os especialistas durante a conferência "Sustentabilidade na Geração e Uso de Energia no Brasil: os Próximos 20 Anos", que ocorreu em fevereiro de 2002, ao afirmarem que:

... não há projeção de futuro energético para a humanidade sem se considerar fontes como as do vento, da luz e do calor solar, da biomassa e até do movimento das marés. Fontes inesgotáveis ou renováveis, que garantam a preservação ambiental, em contraponto com a atual prioridade dada ao petróleo, carvão e gás (TIDEI, 2002).

O leitor atento deve ter observado que, na afirmação antecedente, o potencial hidrelétrico pode ser considerado como uma energia alternativa. E o é, se extraído por meio de Pequenas Centrais 
Hidrelétricas, as PCH. Poderia, então, uma fonte de energia ser, ao mesmo tempo, alternativa ou convencional? A resposta é sim, em função da escala de geração propiciada pela fonte.

O Ministério das Minas e Energia (MME) afirma enfaticamente que o Brasil possui uma posição privilegiada em termos da oferta de fontes renováveis de energia. Revela a Matriz Energética, que representa toda a energia disponibilizada para ser transformada, distribuída e consumida nos processos produtivos do país, que $43,9 \%$ da Oferta Interna de Energia provêm de fontes renováveis, diferentemente do que ocorre com a média mundial, que se reduz a 14\%. Pior ainda ocorre nos países desenvolvidos, que contam com uma oferta de apenas $6 \%$ das renováveis.

De acordo com dados desse Ministério, esse quadro, já favorável ao Brasil, vai ainda tomar novo impulso, graças à implantação das medidas e recursos preconizados pelo PROINFA, sigla do Programa de Incentivo às Fontes Alternativas de Energia Elétrica, criado pela Lei $n^{\circ} 10.438$, de 26/04/2002 e revisto pela Lei $n^{\circ} 10.762$, de 11/11/2003, para ser operacionalizado pelo MME. Em termos gerais, esse Ministério espera que o caráter estrutural dessa norma legal venha a potencializar os ganhos de escala e as oportunidades de pesquisas tecnológicas, apoiar a competitividade industrial nos mercados interno e externo e promover o reconhecimento dos benefícios técnicos, ambientais e socioeconômicos de projetos de geração baseados em fontes limpas e sustentáveis.

Dentre as tecnologias contempladas como fontes alternativas de energia elétrica estão as Pequenas Centrais Hidrelétricas, as fontes de biomassa (lembrando que a matéria orgânica de origem animal ou vegetal que pode ser utilizada na produção de energia é uma forma indireta de energia solar, pois resulta da conversão da energia solar em energia química por meio da fotossíntese, base dos processos biológicos dos seres vivos), e a energia eólica, que retira o potencial cinético das massas de ar em movimento e o converte em eletricidade.

As três opções de tecnologia alcançadas pelas possibilidades de financiamento do PROINFA são para fontes renováveis. A escala de aproveitamento, contudo, determina que sejam de potencial alternativo, ou seja, cada aproveitamento possuirá relativamente pequena capacidade geradora. No seu conjunto, porém, o potencial dessas fontes não tem nada de pequeno: o potencial inventariado do Brasil para pequenos aproveitamentos hidráulicos é de $9.800 \mathrm{MW}$, a saber, 70\% do de Itaipu.

Aproveitando-se as várias formas de biomassa, projeções da Agência Internacional de Energia indicam que o peso relativo da biomassa na geração mundial de eletricidade chegará a 27 TWh em 2020, equivalente a $20 \%$ de Itaipu - note-se, biomassa usada para produzir eletricidade. O Atlas do Potencial Eólico Brasileiro informa que o potencial brasileiro é de $143.000 \mathrm{MW}$, equivalente a mais de 10 centrais como a de Itaipu. A grande diferença é que esses projetos têm distribuição espacial difusa, ao contrário do que acontece, insistindo no exemplo dado, em Itaipu.

Quando, então, se preferir implantar um projeto de geração alternativo ou um convencional? A resposta é similar à pergunta anterior: dependerá da escala de geração propiciada pela fonte.

Já se comentou sobre a interessante diversidade de fontes abarcadas pela Matriz Energética Nacional, que comprova que o Brasil possui grandes possibilidades energéticas.

Vale recordar a diversidade apresentada na figura 6, no qual se destacam como significativas duas fontes renováveis, a biomassa (cana-de-açúcar e lenha) e a hidrelétrica, a par de três outras, esgotáveis (ou não-renováveis): o petróleo, o gás natural e o carvão mineral. Não constam ainda, como significantes, outras energias renováveis, como a eólica, cujo parque não chegava a gerar $1 \%$ do total das ofertas brasileiras em 2005, portanto, abaixo do urânio, energia freqüentemente presente entre as energias limpas, ainda que não-renovável.

A tabela 1 apresenta um panorama de 1994 acerca das tecnologias mundiais relativas às energias renováveis, bem como sua situação quanto ao desenvolvimento tecnológico e ao potencial econômico. Em que pese essas informações estarem, na maioria dos casos, desatualizadas, vale como um estado da arte temporal.

Assim, é importante notar, nessa tabela, que entre as energias da biomassa não se considerava a possibilidade de uso do etanol, biodiesel e óleos animais. Outras tecnologias, que estão registradas como em pesquisa e demonstração, passados esses 12 anos, certamente já possuem resultados conclusivos. Além dos exemplos citados, existem outras tecnologias energéticas aplicadas às diversas fontes citadas. 
Tabela 1. Percepção das possibilidades das energias renováveis em 1994.

Table 1. Perception of the possibilities of renewable energy in 1994.

\begin{tabular}{llcc}
\hline Tecnologia & & Desenvolvimento tecnológico & Situação econômica \\
\hline \multirow{5}{*}{ Biomassa } & Fazendas energéticas & Pesquisa/demonstrado & Econômico \\
& Rejeitos agrícolas & Pesquisa/demonstrado & Econômico \\
& Resíduos urbanos & Pesquisa/demonstrado & Econômico \\
& Biogás & Demonstrado & Econômico \\
\hline \multirow{2}{*}{ Hidrelétrica } & PCH & Desenvolvido & Econômico \\
& Grandes barragens & Desenvolvido & Econômico \\
\hline \multirow{4}{*}{ Solar } & Termelétrica solar & Pesquisa/demonstrado & Não-econômico \\
& Térmica solar & Desenvolvido & Econômico \\
& Arquitetura solar & Desenvolvido & Econômico \\
& Fotovoltaica & Desenvolvido & Econômico (1) \\
& Termoquímica & Desenvolvido/Pesquisa & Econômico (2) \\
& Fotoquímica & Pesquisa & Não-econômico \\
\hline \multirow{3}{*}{ Eólica } & Continental & Desenvolvido & Econômico (1) \\
& Marinha & Desenvolvido & Econômico (2) \\
& Bombas de ar & Desenvolvido & Econômico (1) \\
\hline \multirow{5}{*}{ Oceânica } & Maremotriz & Desenvolvido & Econômico (2) \\
& Correntes marítimas & Pesquisa & Não-econômico \\
& Ondas costeiras & Pesquisa/Demonstrado & Econômico (2) \\
& Ondas marítimas & Pesquisa & Não-econômico \\
& Termoceânica & Pesquisa/Demonstrado & Econômico (1) \\
& Gradiente salino & Pesquisa & Não-econômico \\
\hline \multirow{5}{*}{ Geotérmica } & Desenvolvido & Econômico \\
& Hidrotérmica & Desenvolvido & Não-econômico \\
& Geopressurizada & Pesquisa/Demonstrado & Não-econômico \\
& Rochas quentes & Pesquisas & Não-econômico \\
\hline
\end{tabular}

(1): Econômico regionalmente; (2): Provavelmente econômico regionalmente.

Fonte: IEA/OCED, 1994, apud GOLDEMBERG, 2003.

\section{A regionalização energética brasileira}

As fontes energéticas brasileiras mostram um quadro muito interessante de possibilidades e de dificuldades vocacionais, assim entendendo-se o encontro das oportunidades com as necessidades ou demandas. A oferta potencial das fontes é significativa, porém as distâncias entre os locais de produção e os locais de consumo energético são obstáculo representativo ao aproveitamento desse potencial. Contudo, não são somente as distâncias que estão onerando o custo da exploração de nossos potenciais.

A tabela 2, publicada no Suplemento Energia, da Revista Exame, apresenta um rol de pontos críticos oneradores das fontes energéticas convencionais. É notável nessa lista que, dentre todos os aspectos relacionados com a elevação dos custos energéticos, sejam tão sucintos os questionamento ambientais relacionados ao petróleo. Apesar dos conflitos dessa fonte com a sustentabilidade ambiental, não se notam movimentos ambientalistas com questionamentos representativos.

A propósito, freqüentemente as análises focam o uso dos derivados de petróleo, menos no setor industrial e mais no de transporte rodoviário, e a opinião pública se mantém alheia aos impactos decorrentes da exploração do recurso e de seu refino. São desprezíveis as manifestações pelo desenvolvimento de formas modais diversas de transporte, como o hidro e o ferroviário.

Não se discute também o contínuo crescimento das frotas rodoviárias. É verdade que há divulgação de medidas para reduzir o consumo dos combustíveis com melhorias tecnológicas, porém raras vezes isso ocorre com motivações ambientais: são sempre econômicas.

Nessa linha de raciocínio, vale lembrar que se consideram sofisticação ambiental as medidas de gerenciamento de tráfego e integração do transporte coletivo, mas ainda pouco se fala das necessárias soluções substitutivas da dependência do uso do petróleo pelo de fontes menos poluentes, bem como por outras modalidades de transporte em que os ganhos ambientais sejam mais significativos.

A preservação dessa situação muito provavelmente reside na forma habilidosa com que as empresas do setor automotivo e petroleiras exercem seus lobbies junto às organizações sociais de defesa ambiental, ou porque são muito eficientes em divulgar suas paliativas soluções ambientais. A verdade é

FLORESTA, Curitiba, PR, v. 38, n. 2, abr./jun. 2008. 
que inexistem vozes contestatórias à existência da imensa frota nacional - que não pára de crescer - de veículos automotivos, dos quais - em termos mundiais - 95\% são supridos por combustíveis fósseis.

Tabela 2. Os motivos do aumento dos preços dos combustíveis no Brasil.

Table 2. The causes for the increase of price of fuel in Brazil.

Os motivos do aumento de preço

As fontes mais baratas começam a se esgotar e questões ambientais e políticas encarecem cada vez mais a energia.

\begin{tabular}{c} 
Hidrelétricas \\
$\begin{array}{c}\text { Os potenciais hídricos disponíveis ficam distantes dos centros de consumo, o que exige a construção de um } \\
\text { sistema de transmissão que encarece muito a energia. }\end{array}$ \\
\hline $\begin{array}{c}\text { Termelétricas } \\
\text { As usinas térmicas usam combustíveis como gás e óleo diesel, cujos preços não param de subir. As reservas } \\
\text { nacionais são pequenas e há risco de desabastecimento. }\end{array}$ \\
\hline
\end{tabular}

Fontes alternativas

A energia gerada por vento, sol e ondas do mar pode ser uma opção no futuro, mas ainda não é viável economicamente e demanda grandes investimentos em pesquisas. O desenvolvimento dessas fontes é demorado.

Custos ambientais
$\begin{gathered}\text { Movimentos sociais e de defesa do meio ambiente passaram a exigir maiores compensações para permitir a } \\ \text { implantação de usinas. O custo ambiental saltou de } 10 \% \text { para } 20 \% \text { do investimento. }\end{gathered}$
Regulação
A presença do Estado na regulação do setor e mudanças nas regras provocam insegurança. A falta de ofertas
nos leilões de energia mostra a insatisfação dos investidores.
Petróleo
As reservas do combustível, além de finitas, estão em uma área do globo de muitos conflitos. Sua cotação
disparou nas últimas décadas e nada indica que isso vá mudar.

Fonte: Suplemento Energia, da Revista Exame, abril de 2006.

Mesmo diante dos dados mundiais do esgotamento das jazidas petrolíferas - pelos menos no nível das tecnologias exploratórias atuais - não decresce o volume dos usuários. À eminência do esgotamento desse combustível, nos próximos 30 a 40 anos - a continuarem as demandas mundiais -, causa espanto que alternativas energéticas para essa finalidade sejam ainda tão incipientes.

O intenso consumo dos combustíveis fósseis significa a reativação de volumes energéticos planetários latentes. Em outros termos: os fluxos que regem os processos vitais do planeta, as forças termodinâmicas e suas entropias estão recebendo uma elevada overdose energética. Sendo a energia indestrutível, ela está se transformando em outras modalidades energéticas, algumas, com certeza, desfavoráveis à continuação de pelo menos uma parte da vida planetária.

As emissões decorrentes do consumo desses combustíveis (monóxido de carbono, óxidos nitrosos e sulfurosos, materiais particulados, etc.) são tanto danosas à saúde como são danosos à atmosfera próxima, formando gases de efeito estufa, com reflexos térmicos estimados como de elevada perniciosidade. E mais: são danosos às camadas elevadas da atmosfera, destruindo a camada de ozônio, que constitui valioso escudo protetor contra a letal radiação ultravioleta. É ainda tíbia a reação pública a esses efeitos. É nula a ação mobilizadora efetiva, em benefício de uma solução. Há uma evidente insustentabilidade, porém, a partir da imprensa, parece estar começando a surgir um volume de vozes eminentes reagindo a essa situação.

Os preços dos combustíveis e da energia elétrica, por conta das pressões acima citadas, vêm crescendo, e as projeções apontam para valores realmente elevados em poucos anos. Notícias da imprensa dão conta de incrementos da ordem de $600 \%$ entre 1998 e 2006 no preço dos combustíveis fósseis. Nos custos da energia elétrica, projeções prevêem elevação dos custos em $212 \%$ nos próximos 14 anos (EXAME, 2006). Essas previsões, contudo, não consideram os riscos de convulsões internacionais na região do Golfo Pérsico, plausíveis e capazes de gerar incrementos absolutamente inesperados.

No entanto, elevando-se o preço dos combustíveis convencionais, surgem oportunidades para ativação de outras fontes, antes tidas como economicamente inviáveis, que estão se tornando viáveis, 
notadamente pelo seu avanço tecnológico e difusão do uso. Coincidentemente, ou independentemente de possuir apelo ambiental, é sob essa bandeira que algumas energias alternativas vêm sendo anunciadas. Contudo, não se devem aceitar esses argumentos sem uma adequada reflexão, até porque quem está à frente de tais declarações não comprovou idoneidade para arvorar-se à posição de paladino das causas da sobrevivência planetária.

Nessas reflexões, cabem exames acurados e imposições de efetivas melhorias de processos, visando a ganhos socioambientais efetivos, por via de desenvolvimentos tecnológicos compatíveis.

Esforços para superação das barreiras não são novidade no desenvolvido setor energético e devem ser envidados para otimizar aproveitamentos de potenciais energéticos com reduzidos riscos ambientais e sociais, especialmente quando situados em regiões distantes dos centros consumidores. Este é o grande desafio: atender às demandas nacionais com soluções tecnológicas social e ambientalmente aceitáveis. Regionalizadas. Sustentáveis.

Atraídos justamente por esses desafios, pesquisadores e empreendedores já se debruçam sobre os mapas que mostram a geografia das fontes energéticas nacionais. Já são conhecidas as regiões de maior potencial eólico, os campos petrolíferos, os setores de maior incidência solar, os trechos de rios com maior potencial hidrelétrico e até as poucas zonas costeiras mais apropriadas para a transformação da cinética dos movimentos oceânicos em energia elétrica.

Justamente nesse contexto da nova Era da Diversidade Energética brasileira se descortina sua nova fronteira, a bioenergia - ainda que incitada mais por interesses econômicos do que por qualquer outro (conquanto a bandeira ambientalista sempre esteja por perto para ser desfraldada assim que convier) -, que se aplica a várias finalidades, notadamente no setor de transportes.

Nessas novas propostas, haverá empregos, oportunidades de desenvolvimento rural e facilidades para produtores rurais. São ganhos lícitos e desejáveis. Como obtê-los e concomitantemente produzir o volume desejado de produto energético, preservar as condições sociais e ambientais essenciais (solo, águas puras, vida silvestre, qualidade de vida) com sustentabilidade?

\section{A sustentabilidade da bioenergia}

As análises do Balanço Energético Nacional (BEN) não deixam dúvidas de que os fatores de origem econômica conduziram à adoção de fontes energéticas tanto convencionais como alternativas. Afinal, essa é a mola que impulsiona a civilização contemporânea. Referindo-se ao período de adoção do Plano Real (1994 a 1998), a análise do BEN lembrou que:

(...) o baixo crescimento econômico e as substituições por fontes alternativas, inclusive a substituição de gasolina por álcool, são as causas do pouco ou nenhum desempenho nos demais períodos. A partir de 1999, o uso do gás natural em veículos passa a contribuir, também, para a redução do consumo de derivados. Em 2004 há ligeira recuperação no consumo de derivados, como já comentado em análises anteriores, mas é prematuro afirmar que seja sustentável. (MME, 2006)

Continua a análise do relatório Balanço Energético Nacional:

No que respeita à biomassa, o setor industrial, com cerca de $67 \%$ do consumo (inclui o uso de bagaço na produção de álcool), e o residencial, com cerca de $16 \%$, são os principais consumidores. Em seguida vem o setor de transporte, com $12 \%$, em razão da utilização do álcool carburante. O alto incremento do uso industrial de biomassa, na primeira metade da década de 80 , se deve ao carvão vegetal, em substituição ao óleo combustível, ao bagaço de cana utilizado na produção de álcool e à expansão da siderurgia a carvão vegetal. (MME, 2006)

A lenha para uso no fogão tradicional já não queima mais, mas passou a ser usada para aquecer as caldeiras industriais. O álcool, que teve destaque energético por um tempo e depois decaiu, está voltando, como se verá a seguir. Na figura 8 , é mostrado como essas substituições ocorreram na evolução do consumo das biomassas brasileiras.

A mídia de negócios tem sido veemente na divulgação da bioenergia como nova fronteira energética mundial. São notícias que não deixam dúvidas de que o Brasil está diante de uma oportunidade rara de tornar-se um líder mundial no setor energético, graças às suas características naturais.

FLORESTA, Curitiba, PR, v. 38, n. 2, abr./jun. 2008. 




Fonte: Ministério das Minas e Energia/BEN - Balanço Energético Nacional.

Figura 8. Evolução do consumo setorial de biomassa no Brasil.

Figure 8. Evolution of biomass consumption in Brazil by sectors.

O fortalecimento de tudo certamente se deu quando, em junho passado, o presidente dos EUA, George W. Bush, ao condenar o "vício americano pelo petróleo", autorizou pesquisas pelo Departamento de Energia dos Estados Unidos para etanol derivado da cana-de-açúcar (o etanol americano é produzido a partir do milho). Essa matéria já encontrou a mídia brasileira sensível à questão da bioenergia, que então tomou redobrado alento. Esse passou a ser o assunto do momento, inclusive em periódicos de negócios, como Exame e Gazeta Mercantil.

Ambos os periódicos promoveram edições especiais sobre a questão energética, com detalhes para os biocombustíveis. A Gazeta Mercantil editou um suplemento chamado Balanço Setorial Energia, em junho de 2006, com sete artigos destacando usos energéticos da biomassa, com títulos muito atraentes, por exemplo, "Uma Itaipu cresce nos canaviais do País", "Casca de arroz também produz energia", Biodiesel atrai investimentos à Bahia", "Paraná começa a atrair pólo produtor", entre outros.

A Revista Exame editou um Suplemento em 26 de abril de 2006 denominado Estudo/Energia, com seis grandes artigos, um dos quais é dedicado à bioenergia e outro faz muitas menções às energias alternativas. A ênfase às novas opções energéticas foi ressaltada:

(...) como conseqüência dessa percepção, novas fontes de energia começam a fazer parte da realidade de vários países. Na França, por exemplo, o diesel vendido tem necessariamente de contar com pelo menos $5 \%$ de biodiesel, combustível produzido com a soja - muito menos poluente e muito mais caro. Alemanha e Suécia planejam gerar $30 \%$ da energia que consomem a partir do vento nos próximos 15 anos. São evidências de que a matriz energética internacional se encontra em pleno processo de mudança. Na década de 80 , o petróleo representava $60 \%$ de toda a energia consumida no mundo. Hoje, essa participação é de $40 \%$. Fontes renováveis de energia, como a nuclear, a hidrelétrica, o álcool e o biodiesel, avançam rapidamente e já representam $20 \%$ da matriz mundial. (EXAME Suplemento, 2006)

Mas o citado artigo destaca que a busca por fontes mais limpas e renováveis tem ficado praticamente restrita às nações ricas:

Países em desenvolvimento, em sua grande maioria, continuam usando fontes mais baratas - e que poluem mais. A China, por exemplo, usa carvão para gerar $75 \%$ da energia que consome. O carvão também é amplamente utilizado na Rússia, apesar das grandes reservas de gás que o país possui. Outro peso pesado do mundo emergente, a Índia, tem problemas e precisou aderir aos racionamentos para evitar um colapso. Também os indianos contam majoritariamente com o carvão para manter o país operando. O Brasil é uma exceção. Graças ao imenso potencial hidráulico e a investimentos na construção de usinas em épocas de menor patrulhamento ambiental, o país tem mais de $70 \%$ de sua matriz energética baseada em hidrelétricas, uma das formas mais limpas e baratas de gerar energia. 
Além disso, investiu no desenvolvimento do álcool combustível e hoje lidera essa tecnologia, que desponta como uma das mais promissoras nas próximas décadas. (EXAME Suplemento, 2006)

Vale a pena, ainda, destacar daquela matéria o quadro intitulado "Um mercado em transformação", transcrito na tabela 3, no qual se evidenciam os esforços das grandes nações em se adaptar ao novo cenário de energia escassa e cada vez mais dispendiosa.

Tabela 3. Percepção mundial da transformação do mercado de combustíveis.

Table 3. World perception of the changes in the fuel marketing.

\begin{tabular}{lc}
\hline Um mercado em transformação & $\begin{array}{c}\text { Países de todo o mundo procuram alternativas e tentam se adaptar ao novo } \\
\text { cenário de energia escassa e cada vez mais cara. }\end{array}$ \\
\hline Estados Unidos & $\begin{array}{c}\text { Consomem } 25 \% \text { do petróleo do mundo, mas têm problemas com os maiores } \\
\text { produtores. Buscam alternativas em fontes renováveis, como o álcool e o } \\
\text { biodiesel. }\end{array}$ \\
\hline Brasil & $\begin{array}{c}\text { O maior produtor e exportador de álcool, com } 40 \% \text { do mercado mundial, } \\
\text { desponta como fornecedor global de um combustível renovável. }\end{array}$ \\
\hline França & $\begin{array}{c}\text { Cerca de } 80 \% \text { de sua energia é gerada por usinas nucleares. Com a crise de } \\
\text { abastecimento, o país começa a ser copiado pelos vizinhos da Unão } \\
\text { Européia. }\end{array}$ \\
\hline Alemanha & $\begin{array}{c}\text { É o país que mais investe em energia eólica e tem o maior parque de cata- } \\
\text { ventos do mundo. Até } 2030, \text { pretende gerar 30\% da eletricidade que usa com } \\
\text { a força do vento. }\end{array}$ \\
\hline Rússia & $\begin{array}{c}\text { Tem as maiores reservas de gás natural do mundo - 13\% do total - e, com a } \\
\text { diversificação das fontes de energia, desponta como grande fornecedor. }\end{array}$ \\
\hline China & $\begin{array}{c}\text { Cerca de } 75 \% \text { de sua geração de energia depende do carvão mineral. Para } \\
\text { reduzir a dependência, investiu em Três Gargantas, a maior hidrelétrica do } \\
\text { mundo. }\end{array}$ \\
\hline Arábia Saudita & $\begin{array}{c}\text { Dona de } 24 \% \text { das reservas de petróleo do globo, dá as cartas no mercado, } \\
\text { mas há previsões de que seus poços vão se esgotar em quatro décadas. }\end{array}$ \\
\hline Fonte: Exame. Suplemento Estudo Energia, de 26/04/2006.
\end{tabular}

Nova matéria foi editada em Exame, em sua edição de 21 de junho de 2006, que trouxe o assunto da bioenergia como assunto de capa, com a chamada "Etanol, A Nova Riqueza do Brasil":

(...) O álcool combustível está transformando o país numa potência energética mundial. E o impacto na economia é enorme. Investimentos internacionais. Empregos. Oportunidades de Negócios. Bemvindo à era do Etanol. (EXAME, 2006).

Três longos textos se estenderam sobre o tema, o primeiro destacando os impactos da reativação da opção energética na economia, o segundo anunciando a entrada de um investidor de grande vulto nas pesquisas do etanol e o terceiro discorrendo sobre a tecnologia automotiva flex, que considera um "sucesso mundial".

Na esteira dessas matérias, os maiores jornais do país desenvolveram artigos notáveis. O jornal Folha de S. Paulo publicou uma matéria intitulada "Bioenergia anima e muda agronegócio", em 9 de julho de 2006, destacando que, no Brasil, a "redescoberta do álcool permite que a cana avance sobre outras culturas tradicionais como o café e a laranja". Outra frase a destacar nessa matéria: "Essa febre por agroenergia traz um novo modelo agrícola. Nos EUA já há o surgimento de uma economia agrícola baseada em uma nova industrialização: a do etanol" (BIOENERGIA, 2006).

Na mesma data, outra matéria da Folha de S. Paulo teve como manchete "Mudança nos EUA favorece milho brasileiro", ressaltando que "aumento da demanda do produto na fabricação de combustível abre mais o mercado para exportações do Brasil", e afirmando que "não é apenas o Brasil que ganha com a alta do grão e a abertura do mercado externo: Argentina e China também entram na lista" (MUDANÇA, 2006).

Referindo-se a outra fonte de biomassa, articulistas também entram na onda: Gian Gomes Marques, autor da "Via Expressa" da Gazeta Mercantil, escreveu, em 14/04/06, "Biodiesel, bom para o campo e cidade", destacando as virtudes desse biocombustível, que ainda está em testes, abordando as conveniências à economia rural e para a saúde da população urbana (MARQUES, 2006).

Ainda sobre o biodiesel, Isabel Dias Aguiar, também do jornal Gazeta Mercantil, reporta estudo divulgado pelo Centro de Estudos Avançados em Economia Aplicada (CEPEA), que revela que:

FLORESTA, Curitiba, PR, v. 38, n. 2, abr./jun. 2008. 
Para biodiesel obtido por meio do grão (de soja) como matéria-prima comprada no mercado, em uma usina média, com capacidade de 40 mil toneladas ao ano, o custo final do produto chegou a R\$ 0,0902 na região Norte, o preço mais baixo apurado na pesquisa (AGUIAR, 2006).

Essa matéria revela os custos da mesma escala de produção para várias matérias-primas, em cada uma das cinco regiões brasileiras. É necessário destacar, desses dados, os resultados do que antes se comentou, da preocupação dos especialistas em descobrir as potencialidades das regiões brasileiras, com cálculos sobre a safra 2004/2005. Os números desse estudo estão indicados na tabela 4.

Tabela 4. Atrativos regionais para a produção de biodiesel.

Table 4. Regional attractive aspects to the production of biodiesel.

\begin{tabular}{|c|c|c|c|c|c|c|c|}
\hline \multicolumn{8}{|c|}{ Custo mínimo de biodiesel por região } \\
\hline \multicolumn{2}{|l|}{ Sul } & \multicolumn{2}{|c|}{ Sudeste } & Centro-Oeste & \multicolumn{2}{|c|}{ Norte } & Nordeste \\
\hline Soja & $\mathrm{R} \$ 1,424 / 1$ & Soja & $\mathrm{R} \$ 1,372 / 1$ & $\mathrm{R} \$ 0,952 / 1$ & Soja & $\mathrm{R} \$ 0,902 / 1$ & $\mathrm{R} \$ 0,951 / 1$ \\
\hline \multirow[t]{2}{*}{ Girassol } & $\mathrm{R} \$ 0,889 / 1$ & Girassol & $\mathrm{R} \$ 0,859 / 1$ & Girassol R\$ 1,253/1 & Dendê & $\mathrm{R} \$ 1,324 / 1$ & Mamona R\$ 2,219/1 \\
\hline & & Amendoim & $\mathrm{R} \$ 1,874 / 1$ & Algodão R\$ 0,975/1 & & & Algodão R \$ 0,712/1 \\
\hline
\end{tabular}

Fonte: AGUIAR, 2006.

Uma nova notícia da Gazeta Mercantil, assinada por Chiara Quintão, em 10 de julho de 2006, coloca em evidência outra fonte de energia, o sebo animal, para a fabricação de biodiesel. A matéria, com o título "Biodiesel de sebo atrai investimentos", revela que "expansão do setor pode ser limitada por oferta restrita de matéria-prima" e que "a produção de biodiesel de sebo no Brasil está atraindo o interesse das indústrias, especialmente frigoríficos". Essa reportagem menciona que uma indústria de adubos já obteve todas as licenças da Agência Nacional de Petróleo, Gás Natural e Biocombustíveis (ANP) e está produzindo biodiesel desde janeiro deste ano. Especialistas do setor afirmam, contudo, que o crescimento dessa produção poderá gerar conflitos envolvendo a matéria-prima, tendo em conta que o sebo já tem outras aplicações. Diz o jornal que a produção de sebo no Brasil é de cerca de 500 mil toneladas anuais.

Retornando ao etanol, não deveria surpreender a notícia procedente da Petrobrás, de sua entrada grandiosa na exploração desse combustível. A manchete da Gazeta Mercantil, em seu editorial de 6 de julho de 2006, deu o tom da pretensão da multinacional brasileira: "O futuro 'dono' do álcool”. O módulo do projeto pioneiro previu atrair 40 proprietários de terras capazes de produzir 5 mil litros por hectare/ano, alcançando 7,5 mil hectares de terras agrícolas, suficientes para a produção de $500 \mathrm{mi}$ toneladas de cana por safra, suficientes para gerar 37,5 milhões de litros de álcool.

Essas terras devem estar situadas no Centro-Oeste, no sul da Bahia e no Triângulo Mineiro. A todas as terras que apresentarem esse potencial de produtividade, a Petrobrás oferecerá um contrato de compra firme de álcool de 20 anos, vinculado a fundo de investimento, organizado pela Petrobrás, para levantar recursos para o empreendimento junto ao BNDES e ao Japan Bank.

A matéria da Gazeta Mercantil informa mais:

Estes financiadores estão atentos à demanda internacional prevista para o produto. O mercado norteamericano e o asiático já desenvolveram projetos para acomodar o álcool como matriz energética prioritária, até por razões ambientais. O Japão já decidiu, em lei, pela adição de $3 \%$ de álcool na gasolina até 2007, com evolução prevista para $10 \%$ até 2012. A estatal brasileira já marcou presença no mercado japonês com a abertura de joint-venture com a trading japonesa Nipon AIcohol Banhai para ativar importação e exportação do produto. Transformar álcool em commodity exige alcançar escala suficiente para equilibrar oferta e demanda. É exatamente o que a Petrobrás começa a fazer. (GAZETA MERCANTIL, 2006)

Por mais atraentes que sejam esses programas, há notícias de que as iniciativas privadas no Brasil já vêm enfrentando vários problemas. A instalação de 70 novas usinas nas regiões oeste e norte paulista, por exemplo, vem sendo postergada por obstáculos que vão da negação das licenças ambientais até a brusca inflação dos preços de arrendamento das terras agrícolas.

Finalmente, notícias do O Estado de São Paulo dessa data (15 de julho de 2006), fazendo menção de artigo publicado no The Wall Street Journal, informa que o representante brasileiro Presidente Lula - "deverá apresentar aos líderes do G-8, a experiência brasileira de produção e aplicação do etanol e de outros recursos renováveis, como o biodiesel e o H-Bio".

De acordo com esse jornal, estão sendo citados números convincentes entre os argumentos preparados para a ocasião, desde as vantagens da: 
(...) adição de $20 \%$ de etanol à gasolina, da venda de etanol em mais de 30 mil postos de combustíveis até o fato de o etanol representar $40 \%$ do combustível consumido por veículos de passageiros no Brasil. Acrescenta ainda que $80 \%$ dos carros novos vendidos no Brasil são bicombustíveis tecnologia adotada em 2003. "Desde a década de 70, o etanol substituiu cerca de 800 milhões de barris de petróleo por dia, o equivalente a quase dois anos da produção corrente de petróleo no Brasil", assinala o Presidente. "Naturalmente, nós sabemos que o etanol não é a única solução para os problemas de suprimento de combustível. Mas, com certeza, pode se tornar parte da solução. O aumento substancial do consumo de etanol pode estender os recursos mundiais, adiando a data de esgotamento das reservas", completou. (ESTADO DE SÃO PAULO, 2006)

Como se pode notar, a difusão dessa alternativa energética está mostrando um raro vigor, cuja exuberância gera grandes expectativas de benefícios econômicos. Esses benefícios poderão ser obtidos realmente. Propiciarão uma etapa de crescimento, e muitas pessoas, famílias e comunidades poderão ser alcançadas por ele.

Nesse arroubo econômico, contudo, existem riscos e ameaças que devem ser considerados e devidamente tratados, compensados, mitigados, resolvidos. Vale levantar algumas expectativas negativas advindas dessas monoculturas:

- A monocultura da soja, as plantações de algodão e milho e a agricultura mecanizada como um todo são os principais fatores responsáveis pela destruição do cerrado. As áreas mais ameaçadas, segundo o estudo da Conservation International, estão no sul do Maranhão e do Piauí e no oeste da Bahia (MEIO, 2005).

- Todas as monoculturas são artificiais e também muito mais suscetíveis às pragas, que proliferam justamente por não encontrar as resistências próprias dos ambientes naturais.

- As espécies das quais se obtém a bioenergia são, em geral, introduzidas, ou seja, são exóticas. Essa introdução de espécies alóctones pode gerar conflitos genéticos e perdas de espécies autóctones de grande importância ecológica.

- Leonardo Boff, em seu ensaio "Biodiversidade e novo Paradigma", afirmou que "a monocultura é contrária à lógica da natureza, que sempre consorcia todo tipo de formas de vida, permitindo que uma espécie ajude a outra a sobreviver e, ao mesmo tempo, se mantenha o equilíbrio dinâmico de todo o processo natural. Cada implantação de uma monocultura significa um verdadeiro assassinato de espécies vivas, de insetos e microorganismos. Junto com a monocultura vêm os agrotóxicos, necessários para garantir e aumentar a produtividade" (BOFF, 2006).

- Plantios de espécies bioenergéticas em áreas com vulnerabilidade ambiental, como em Áreas de Preservação Permanente e Reservas Legais, no entorno de Unidades de Conservação etc., podem gerar problemas ambientais àquelas áreas protetoras.

- Outro problema do plantio de espécies bioenergéticas poderá ser a contaminação de rios pelo uso de defensores e herbicidas. A experiência das áreas florestais é aplicável às bioenergéticas: jamais a introdução de espécies energéticas vai compensar os danos ambientais que cultivos extensos de espécies bioenergéticas geraram para a região, tampouco para contribuir para a recuperação das matas nativas.

- Cultivos massivos podem fazer com que pequenos agricultores da região sejam expulsos de suas terras por conta da pressão dos demais usuários.

- A proliferação de pequenas usinas processadoras dos biocombustíveis acarretará maior fluxo de veículos transportadores dos combustíveis produzidos, com aumento do número de acidentes. Isso vale ser previsto e contingenciado com medidas apropriadas para controlar tais riscos.

Mais recentemente - e nas esferas políticas internacionais -, vem se comentando que o uso de áreas de produção de grãos úteis à alimentação para a produção de espécies bioenergéticas poderá acentuar os problemas da fome mundial.

\section{CONCLUSÕES}

De acordo com os estudos feitos, conclui-se que há um evidente despertar da imprensa brasileira às questões energéticas, tanto por suas repercussões econômicas como pelas ambientais. Esse despertar se tornou notável pelo aprofundamento observado nas matérias divulgadas, cujo teor - respeitando-se os enfoques preferidos pela imprensa popular - tem correspondido aos avanços tecnológicos desse

FLORESTA, Curitiba, PR, v. 38, n. 2, abr./jun. 2008. 
importante setor econômico. Destacam-se, também, os esforços para compatibilizar a adequada interpretação da terminologia técnica à compreensão popular.

A mídia tem observado, de forma ampla, que as questões relativas à energia possuem três componentes justapostos: a disponibilidade energética, os custos das transformações da fonte energética em energia útil e as questões socioambientais - incluindo nestas as vertentes da sustentabilidade - que envolvem os processos de obtenção (seja de produção ou de extração), de transformação (incluindo o transporte, o beneficiamento e a distribuição) e de utilização do produto energético (com seus resíduos sólidos, gasosos e térmicos).

No seu conjunto, a imprensa tem reconhecido que o Brasil é bem sucedido em pelo menos três áreas do setor energético: o hidrelétrico, o dos combustíveis fósseis e o das energias alternativas. No campo das hidrelétricas, tem se realçado que a proliferação de usinas atende com segurança, através da energia das águas, a demanda nacional de energia elétrica. Os enfoques da imprensa nesse setor decorrem, não raro, das pressões exercidas pelas organizações do terceiro setor, em favor da proteção de elementos ambientais e sociais atingidos por novos empreendimentos.

A segunda área tratada pela imprensa foi o aumento da produção petroleira brasileira, que atingiu a suficiência nacional dessa fonte energética. O espaço dedicado a esse sucesso brasileiro teve maior incremento diante da decisão do governo boliviano de estatização do gás natural. Notaram-se então evidências da citada especialização da imprensa, quando o jornal Gazeta Mercantil destacou que, dessa dificuldade imposta, poderia emergir novo avanço tecnológico nacional, dirigido para o aproveitamento do gás natural produzido nos campos petrolíferos brasileiros, cujo volume que vinha sendo extraído e desperdiçado por queima nos flares ou por re-injeção nos poços foi estimado em $66 \%$ do volume importado diariamente da Bolívia (CARDOSO, 2006).

A terceira área destacada pela mídia foi o conjunto das chamadas energias alternativas, entre as quais se destaca a tecnologia do álcool combustível, obtido a partir da cana-de-açúcar, que se originou e sustentou a suficiência energética brasileira na crise petroleira dos anos 70. Depois de um período de calmaria - imposta pela queda do preço do petróleo -, foram amplas as informações da mídia de que essa fonte energética retornava ao cenário econômico brasileiro com renovado vigor, despontando como uma das grandes alternativas energéticas globais.

Não passou incólume na imprensa o fato de que outras alternativas energéticas vêm despontando com sucesso econômico, como é o caso da geração eólica, com vários textos comentando que o parque eólico está apresentando crescimento vigoroso. O mesmo se pode dizer acerca das pesquisas sobre o biodiesel, obtido de fontes fotossintetizadoras. A imprensa tem destacado os biocombustíveis, com várias considerações sobre os aspectos ambientais destacados.

Em tudo isso, percebe-se na imprensa a preocupação subjacente por um equilíbrio social e ambiental nos conteúdos das matérias mais importantes, tanto na obtenção dos recursos energéticos, sejam estes de origem hidráulica, sejam de origem fóssil ou das várias fontes alternativas, como na exposição das novas tecnologias de utilização energética.

Assim, reconhecendo-se a inauguração do que a imprensa já chamou de Era da Diversidade Energética, nota-se que a imprensa despertou para esse segmento econômico de alta relevância social e vem exercendo um interessante papel no desenvolvimento sustentável desse setor. Isso foi feito quando favoreceu seu crescimento e a discussão popular, que leva ao aumento da participação da sociedade nas questões inerentes, permitindo empreendimentos energéticos duradouros, cujos eventuais conflitos e incompatibilidades sejam resolvidos, ou pelo menos controlados. Concomitantemente, no rastro dos benefícios desse processo, podem-se esperar novos avanços, gerando oportunidades de empregos, com resultados francamente favoráveis ao meio ambiente e aos recursos naturais.

\section{REFERÊNCIAS}

AGUIAR, I. S. CEPEA mostra a direção do biodiesel. Gazeta Mercantil, São Paulo, 11 maio 2006, p B-12. BIOENERGiA anima e muda agronegócio. Folha de S. Paulo, São Paulo, 09 jul. 2006.

BOFF, L. 2006. Biodiversidade e novo paradigma. Disponível em: $<$ http://www.sinsprev.org.br/index.php?INTEGRA=6963\&TAB>. Acesso em: 07/2006. CARDOSO, D. Pais perde US\$ 5,6 bilhões com desperdício do gás. Gazeta Mercantil, São Paulo, maio 2006. Edição 15. 
BRASIL. Ministério de Minas e Energia. BEN - Balanço Energético Nacional. Disponível em: $<$ http://www.mme.gov.br>. Acesso em: jul. 2006.

ETANOL, A Nova Riqueza do Brasil, Revista EXAME, São Paulo, 21 jun. 2006.

ESTUDO energia Revista EXAME / Suplemento Energia, São Paulo, 26 abr. 2006.

O FUTURO “dono” do álcool. Gazeta Mercantil. Editorial, São Paulo, 06 jul. 2006.

GOLDEMBERG, J. Energia, meio ambiente e desenvolvimento. São Paulo: Edusp, 2003. p. 130.

HINRICHS, R. A.; KLEIBACH, M. Energia e meio ambiente. São Paulo:Thompson, 2003. 542 p.

MARQUES, G. G. Biodiesel, bom para o campo e cidade. Gazeta Mercantil / Via Expressa, São Paulo, 14 abr. 2006.

MEIO Ambiente. Disponível em: <http://agenciacartamaior.uol.com.br>. Acesso em: jul. 2006.

MUDANÇA nos EUA favorece milho brasileiro. Folha de São Paulo, São Paulo, 9 jul. 2006.

PETRÓLEO vira foco de atenção do G-8. O Estado de São Paulo, São Paulo, 15 jul. 2006.

PREPARE-SE para Energia Mais Cara. Revista EXAME / Suplemento Energia São Paulo, 26 abr. 2006. p $2-6$.

QUINTÃO, C. Biodiesel de sebo atrai investimentos. São Paulo: Gazeta Mercantil 10 jul. 2006. p B-12

RIBEIRO, S. K.; REAL, M.V. Novos combustíveis. Rio de Janeiro: E-papers, 2006. 93 p.

ROSA, M. A síndrome de Aquiles: como lidar com as crises de imagem. São Paulo: Gente, 2001. 248 p.

TIDEI, C. O futuro energético. Campinas : Jornal da UNICAMP, 2002. Edição de abril de 2002.

TOLMASQUIN, M. T. (Org). Fontes Renováveis de Energia no Brasil. Rio de Janeiro: Interciência e Cenergia, 2003. $515 \mathrm{p}$.

WOLF, M. Nosso futuro energético mundial. Valor Econômico, São Paulo, 28 jun. 2006. 